\title{
ANÁLISE DA (IN) EFICÁCIA DO DIREITO À CONSULTA PRÉVIA AOS POVOS INDÍGENAS NO BRASIL
}

\section{ANALYSIS OF (IN) EFFECTIVENESS OF THE RIGHT TO PRIOR CONSULTATION TO INDIGENOUS PEOPLES IN BRAZIL}

\author{
${ }^{1}$ Lucas Rodrigues Vieira \\ ${ }^{2}$ Erica Fabiola Brito Tuma
}

\section{RESUMO}

O presente trabalho pretende analisar como o direito à consulta prévia, livre e informada tem sido efetivado aos povos indígenas no Brasil. Primeiramente, será analisada a proteção a nível internacional desse direito às comunidades indígenas. Serão estudadas a Convenção ${ }^{\circ}{ }^{\circ} 169$ da OIT e a Declaração das Nações Unidas sobre o Direito dos Povos Indígenas, bem como a importância dos Mecanismos Internacionais de Direitos Humanos. Após isso, será dado enfoque ao Sistema Interamericano de Direitos Humanos. Por fim, será realizada a discussão quanto à concretização do direito à consulta no Brasil aos povos indígenas.

Palavras-chave: Povos indígenas; Direito à consulta; Direitos humanos; Concretização; Brasil.

\begin{abstract}
This paper aims to analyze how the right to prior, free and informed consultation has been effected to indigenous peoples in Brazil. First, the protection will be discussed at the international level such rights to indigenous communities. Will study the ILO Convention 169 and the UN Declaration on the Rights of Indigenous Peoples, as well as the importance of International Mechanisms of Human Rights. After that, focus will be given to the interAmerican human rights system. Finally, it will be held discussion on the realization of the right to consultation of indigenous peoples in Brazil.
\end{abstract}

Keywords: Indigenous peoples; Right to consultation; Human rights; Realization; Brazil.

\footnotetext{
${ }^{1}$ Mestrando em Direito pelo Programa de Pós-Graduação em Direito da Universidade Federal do Pará - UFPA, Belém, (Brasil). E-mail: rvieiralucas@gmail.com

${ }^{2}$ Mestranda em Direito pelo Programa de Pós-Graduação em Direito da Universidade Federal do Pará - UFPA, Belém, (Brasil). E-mail: e.fabiolatuma@gmail.com
} 


\section{INTRODUÇÃO}

Os povos indígenas são comunidades que apresentam traços culturais e modo de viver próprios que os distinguem do restante da sociedade, como a relação coletiva e espiritual mantida com as suas terras e modo de viver tradicionais e os recursos naturais que o circundam (ESTUPINÃN SILVA \& IBÁÑEZ RIVAS, 2014, p. 293).

Estimam-se que mais de 370 milhões de pessoas sejam consideradas indígenas, distribuídas em cerca de 90 países, sendo que representam 15 por cento dos pobres no mundo e um terço dos extremamente pobres (BURGER, 2014, p. 205).

No contexto da América Latina, os povos indígenas podem ser definidos como aqueles que mantém continuidade histórica com os grupos anteriores a chegada dos primeiros europeus, conservando a forma de organização, as tradições e os idiomas de origem pré-hispânicos (STAVENHAGEN, 2011, p. 24).

Como afirma José Martínez Cobo, faz-se necessária à caracterização da pessoa indígena a presença de dois elementos: a autoidentificação como indígena, que seria a consciência de grupo; e o reconhecimento desses povos como sendo seu membro, o que representa a aceitação pelo grupo (BURGER, 2014, p. 207).

Estes povos são marcados por um processo histórico de graves violações aos seus direitos humanos. Sofreram com o colonialismo, com a expropriação de suas terras e recursos naturais, com a perda dos seus costumes e identidade cultural, de etnocídio e de discriminação, dentre outras mazelas. Assim, historicamente, e atualmente, são grupos em condição de vulnerabilidade e marginalidade (BURGER, 2014, p. 206).

Apesar da condição de vulnerabilidade ao longo do tempo, a discriminação social, política e cultural, os povos indígenas têm uma posição de resistência em busca da preservação de identidade, seus costumes e valores (BURGER, 2014, p. 206).

No contexto nacional, o aumento do protagonismo indígena ocorreu nos anos de 1970 e 1980, quando as reivindicações desses povos ganharam mais força e visibilidade, com manifestos, protestos e denúncias a autoridades internacionais, que resultou na conquista de diversos direitos, antes não reconhecidos. Isso ocorreu em resposta à intensificação da exploração dos territórios indígenas, como, por exemplo, a construção da malha viária na Amazônia, referentes aos empreendimentos da Belém-Brasília, BR 80, Perimetral Norte, Transamazônica (ASSIS \& BELTRÃO, 2014, p. 253). 
Dentre esses direitos conquistados, merece relevo o direito à consulta prévia, livre e informada (ESTUPINÃN SILVA \& IBÁÑEZ RIVAS, 2014, p. 314) aos povos indígenas, direito que visa garantir a esses povos o poder de efetivamente opinar e participar das tomadas de decisões, sejam administrativas ou legislativas, que irão afetar seus bens e direitos. Representa uma maneira pela qual seus anseios possam ser ouvidos e atendidos, sempre tendo em vista a manutenção das suas terras, territórios, recursos e cultura.

Cabe, incialmente, analisar como esse direito é protegido a nível internacional, por meio da Convenção n ${ }^{a}$ 169/1989 sobre Povos Indígenas e Tribais dos Países Independentes da Organização Internacional do Trabalho (OIT), da Declaração das Nações Unidas sobre o Direito dos Povos Indígenas (2007) e dos Mecanismos Internacionais de Direitos Humanos.

Cumpre analisar também o Sistema Interamericano, especialmente quanto à Convenção Americana de Direitos Humanos (1969) e à atuação da Corte Interamericana de Direitos Humanos.

Ultrapassados esses pontos, o presente trabalho enfocará a forma como o direito à consulta prévia aos povos indígenas vêm sendo aplicado e efetivado no Brasil, objetivando concluir se é ou não de maneira adequada e benéfica à preservação da identidade étnica desses povos.

\section{A PROTEÇÃo INTERNACIONAL CONFERIDA AO DIREITO À CONSULTA PRÉVIA}

A Convenção $n^{\circ} 169$ da OIT (1989), aprovada na 76ª Conferência desta organização ocorrida em 1989, surgiu em substituição à antiga Convenção no 107 de 1957 (ESTUPINÃN SILVA \& IBÁÑEZ RIVAS, 2014, p. 314) que possuía caráter eminentemente assimilacionista que visava a integração dos povos indígenas, tribais e "semitribais" à comunidade nacional, com a consequente perda de seus costumes e tradições.

O rompimento dessa visão integracionista é observado já no preâmbulo da referida Convenção, ao reconhecer aos povos indígenas o direito de assumir o controle de suas próprias instituições, formas de vida e seu desenvolvimento econômico, para, assim, poder manter e fortalecer suas identidades, línguas e religiões.

A Convenção $\mathrm{n}^{\circ} 169$ da OIT é o instrumento internacional que aborda de forma mais clara e precisa o direito à consulta prévia, estipulando em seu artigo $6^{\circ}$ a obrigação dos Estados em consultar os povos que serão diretamente afetados por suas medidas legislativas ou 
administrativas, consulta essa que deverá ser permeada pela boa-fé, a fim de se chegar a um acordo e consentimento adequados. Determina, ainda, o estabelecimento de mecanismos pelos quais os povos interessados possam participar efetivamente das tomadas de decisões, fornecendo-se os recursos necessários para esse fim.

Desse modo, constituí dever do Poder Público ouvir e atender, antes de adotar qualquer medida, as demandas dos povos indígenas, garantindo-lhes os meios eficazes de participação e informando-lhes, adequadamente, do projeto e da política que se pretende aplicar, tendo sempre em vista a boa-fé, caso contrário deverá ser anulado o ato (COURTIS, 2009, p. 55).

Como decidiu a Corte Constitucional da Colômbia, ao declarar a inconstitucionalidade da Lei Geral Florestal (Lei n ${ }^{\circ} 1021$ de 2006), com base no art. $6^{\circ}$ da referida Convenção, eis que aprovada sem a consulta adequada às comunidades indígenas e afrodescendentes que seriam afetadas pela mencionada norma, em razão de definir critérios de exploração de áreas onde esses povos se encontram, principalmente quanto à estreita relação que mantém com os bosques (COURTIS, 2009, p. 66).

Ratificada pelo Brasil em 2002 pelo Decreto Legislativo no ${ }^{\circ}$ 143, entrando em vigor desde 2003, a Convenção $n^{\circ} 169$ da OIT tem caráter vinculante, estando incorporada ao ordenamento jurídico interno, ou seja, impõe obrigações que devem ser seguidas pelo governo brasileiro sob pena de sanções internacionais, então é dever deste assegurar aos povos indígenas o direito à consulta prévia, livre e informada.

Há discussões em relação à hierarquia das normas internacionais incorporadas ao sistema jurídico interno. É incontestável que os tratados de direitos humanos aprovados nos moldes do $\S 3^{\circ}$ do artigo $5^{\circ}$ da Constituição Federal de 1988, incluído pela Emenda Constitucional $n^{\circ} 45 / 2004$, possuem hierarquia constitucional. Em contrapartida, os que não foram aprovados por esse procedimento especial seriam integrados como simples leis ordinárias, porém como a maioria dos tratados internacionais sobre direitos humanos foram ratificados antes dessa alteração, não poderiam ser atingidos por ela.

Assim, abre-se cada vez mais espaço à interpretação da supralegalidade das normas internacionais, em que estariam em patamar intermediário: inferior à Constituição, contudo superior à legislação ordinária

O Supremo Tribunal Federal (STF) já decidiu que as Convenções da OIT servem como reforço de arguição de inconstitucionalidade, situando-as no mesmo plano das leis ordinárias ${ }^{3}$.

\footnotetext{
${ }^{3}$ No julgamento da ADI no 1675 MC/DF, o Ministro Sepúlveda Pertence defendeu que: "A Convenção 126 da OIT reforça a arguição de inconstitucionalidade: ainda quando não se queira comprometer o Tribunal com a tese
} 
Porém, a Corte Constitucional reconheceu em outros julgados a posição supralegal assumida pelas normas internacionais de direitos humanos ${ }^{4}$.

A importância da supralegalidade reside na possibilidade da utilização das normas internacionais de direitos humanos como parâmetro de interpretação não apenas dos diplomas legais, como também da própria Constituição, o que lhes conferem maior efetividade (MAUÉS, 2009, p. 45). Desse modo, a Convenção n ${ }^{\circ} 169$ da OIT deve orientar e vincular atuação do Estado, pois defende direitos essenciais à proteção dos povos indígenas, como o direito à consulta.

Outro instrumento internacional utilizado para a proteção dos povos indígenas é a Declaração das Nações Unidas sobre o Direito dos Povos Indígenas, aprovada em 2007 pela Assembleia Geral, após 23 anos de debates (ONU, 2007). A iniciativa da elaboração desta declaração foi do Grupo de Trabalho sobre Populações Indígenas (GTPI), criado em virtude dos estudos realizados pelo Relator Especial José Martínez Cobo.

É certo que esta Declaração não atende todas as demandas indígenas, devendo, na verdade, ser considerada como um conjunto mínimo de direitos a serem garantidos a esses povos. Apesar disso, é essencial por proteger os direitos coletivos dos povos indígenas e garantir o direito à autoderminação, permitindo que se desenvolvam e explorem suas terras e seus recursos naturais da forma que melhor lhes convir.

Em seu art. 18, a Declaração (ONU, 2007) prevê o direito dos povos indígenas à participação nas tomadas de decisões que irão afetar seus interesses, por meio de representantes eleitos consoante seus próprios procedimentos. Enquanto que o art. 19 impõe aos Estados o dever de consultar e cooperar de boa-fé os povos indígenas interessados, com intuito de se obter um consentimento livre, prévio e informado antes de empregar qualquer medida legislativa ou administrativa.

Portanto, procura-se manter um diálogo mais adequado entre o poder estatal e povos indígenas, baseado na confiança e transparência entre as partes, a fim de chegar a acordos e

\footnotetext{
da hierarquia constitucional dos tratados sobre direitos fundamentais ratificados antes da Constituição, o mínimo a conferir-lhe é o valor de poderoso reforço à interpretação do texto constitucional que sirva melhor à sua efetividade: não é de presumir, em Constituição tão ciosa da proteção dos direitos fundamentais quanto a nossa, a ruptura com as convenções internacionais que se inspiram na mesma preocupação."

${ }^{4}$ No julgamento do RE 349.703 RS, o Ministro Gilmar Mendes arguiu que: “(...) o caráter especial desses diplomas internacionais sobre direitos humanos (o Pacto Internacional dos Direitos Civis e Políticos e a Convenção Americana sobre Direitos Humanos - Pacto de San José de Costa Rica) lhes reserva lugar específico no ordenamento jurídico, estando abaixo da Constituição, porém acima da legislação interna. O status normativo supralegal dos tratados internacionais de direitos humanos subscritos pelo Brasil, dessa forma, torna inaplicável a legislação infraconstitucional com ele conflitante, seja ela anterior ou posterior ao ato de ratificação."
} 
soluções acerca das medidas que se pretende aplicar, para que não afetem as práticas sociais, econômicas e culturais desses grupos. Busca maior participação dos povos indígenas nas tomadas de decisões, assegurando-lhes que seus anseios sejam observados.

Ainda que se reconheça que a referida Declaração não tenha força vinculante, trata-se de um compromisso internacional assumido pelo Estado brasileiro que aprovou as suas disposições. Dessa forma, este possui o dever de efetivá-las e utilizá-las como critério interpretativo à aplicação de outras normas, caso contrário, será mera formalidade, não se protegendo os direitos dos povos indígenas reconhecidos pela comunidade internacional como relevantes.

Dentre os dispositivos desta Declaração, o Poder Público brasileiro deve embasar a sua atuação respeitando o direito à consulta prévia aos povos indígenas antes da implementação de qualquer projeto, posto que visa impedir a violação a direitos humanos fundamentais desses grupos, tais como à igualdade, à autodeterminação, aos direitos territoriais, aos recursos naturais e ao desenvolvimento consoante sua cultura.

Em relação aos Mecanismos Internacionais de Direitos Humanos voltados à questão indígena, podemos destacar: o Relator Especial sobre os Direitos dos Povos Indígenas, o Fórum Permanente sobre Questões Indígenas e o Mecanismo de Especialistas sobre os Direitos dos Povos Indígenas (BURGER, 2014, p. 205).

O Relator Especial é um expert nomeado pelo Conselho de Direitos Humanos da Organização das Nações Unidas (ONU) que será responsável por uma temática específica de direitos humanos, com atribuição de elaborar relatórios, receber denúncias de violações de direitos humanos e comunica-las aos países, realizar visitas oficiais aos países e apresentar recomendações.

A nomeação de um Relator exclusiva à causa indígena representa um significativo avanço e revelo à proteção e promoção dos direitos dos povos indígenas, tendo-se uma pessoa voltada a analisar a sua situação, a comunicar aos Estados as suas reivindicações e buscar soluções amistosas aos conflitos.

Em 2009, o Relator Especial James Anaya apresentou relatório (ONU, 2009) acerca da situação dos direitos humanos e liberdades fundamentais indígenas no Brasil, após visita ao país, na qual realizou reuniões com membros do governo, povos indígenas, representantes das Nações Unidas e da sociedade civil, apresentando conclusões e recomendações. 
Neste documento, atestou-se a existência de discriminação dos povos indígenas não tendo participação nas decisões que os afetem, sofrendo ameaças à integridade cultural e vivendo em condições precárias de vida.

O Relator Espacial advertiu a ausência de mecanismos efetivos de consulta aos povos indígenas relativa aos projetos de desenvolvimento, especialmente quanto à mineração e à hidrelétricas, que geram impactos aos seus interesses. Observou a falta de procedimento de consulta adequado aos padrões internacionais: nas ações do Programa de Aceleração do Crescimento (PAC); na construção de barragens nos rios Xingu, Tocantins, Madeira, Estreito, Tibagi, Juruena, Contigo e Kuluene; na transposição do rio São Francisco; na construção das hidrelétricas de Turucuí e Belo Monte; e no projeto de Integração Regional de Estrutura da América do Sul (IIRSA), o que vem a afetando a vida dos povos indígenas.

Diante desse quadro, o Relator recomendou ao Governo brasileiro a elaboração de uma lei ou outro mecanismo apropriado que defina um procedimento de consulta aos povos indígenas, procedimento este a ser criado com a participação ativa desses grupos, que deverá ser aplicado e respeitado, principalmente, em relação aos projetos de desenvolvimento e atividades de extração de recursos naturais que possam geram impactos direitos sobre os povos indígenas, ainda que essas atividades sejam praticadas fora das terras indígenas demarcadas.

Este relatório demonstra a relevância da atuação de um Relator Especial, fazendo uma pesquisa detalhada acerca da situação dos povos indígenas em diversos países, em que aponta as principais carências e necessidades desses grupos, e, ao final, apresenta recomendações que buscam efetivar os direitos humanos destes.

O Fórum Permanente sobre Questões, estabelecido em 2000 pelo Conselho Econômico e Social da ONU, é formado por dezesseis especialistas independentes, sendo oito eleitos pelos governos e oito pelas organizações indígenas, que realizam reuniões anuais. Tem a tarefa de examinar a problemática indígena relacionada ao desenvolvimento, à educação, à cultura, à saúde e aos direitos humanos, como também colaborar e assessorar a atuação dos órgãos da ONU.

O informe da $14^{\text {a }}$ Sessão do Fórum realizada em 2015 em Nova Iorque (ONU, 2015) aborda várias recomendações acerca da necessidade de se melhorar o diálogo com os povos indígenas e em garantir a consulta aos seus interesses e a participação nas tomadas de decisões.

Dentre essas recomendações, podemos citar a elaboração e definição, pelo Secretário Geral Adjunto para os Assuntos Econômicos e Sociais, de um procedimento que garanta a participação direta dos representantes indígenas nos planos de ações da ONU destinados a 
promover e proteger os direitos humanos dos povos indígenas. Ainda, o estabelecimento, por parte da Assembleia Geral da ONU, de um procedimento que assegure a participação efetiva dos povos indígenas na $70^{\mathrm{a}}$ sessão desta Assembleia.

O Mecanismo de Especialistas sobre o Direito dos Povos Indígenas, criado em 2007 pelo Conselho de Direitos Humanos da ONU, é composto por cinco especialistas indígenas com atribuição de realizar estudos temáticos sobre a questão indígena, organizando sessões anuais com a participação de representantes de Estados, povos e organizações indígenas, e da sociedade civil.

Em estudo apresentado em 2011 (ONU), o Mecanismo de Especialistas define como "boas práticas" aquelas que: permitem e melhoram a participação dos povos indígenas nas tomadas de decisões; conferem aos povos indígenas o poder de influenciar nas decisões que lhes afetem; garantem o direito à autodeterminação aos povos indígenas e asseguram procedimento e/ou processos de consulta adequados à obtenção de consentimento livre, prévio e informado.

O documento adverte que os povos indígenas constituem um dos setores mais marginalizados e excluídos da sociedade, o que impede de determinarem os seus próprios rumos. Em razão disso, merecem proteção especial, em que é consagrado, no direito internacional, o direito aos povos indígenas de se organizarem conforme seus costumes e tradições, bem como à consulta por procedimentos, permeados pela confiança e transparência, que permitem a expressão plena de suas opiniões e influir no resultado das decisões, para se chegar ao acordo ou consenso.

Conclui que os Estados têm a obrigação de promulgar e aplicar as disposições constitucionais e outras disposições legais que reforcem a participação dos povos indígenas na tomada de decisões, e de garantir que esses grupos detenham capacidade técnica e financeira necessária para participar de consultas e de atividades voltadas ao seu consentimento. Às Nações Unidas, cabe estabelecer mecanismo ou sistema permanente de consulta aos órgãos deliberantes dos povos indígenas. À OIT, garantir a participação a esses povos nos processos de aplicação e supervisão dos seus convênios e políticas que tratam de interesses indígenas. E às instituições nacionais de direitos humanos, incumbe a tarefa de contribuir com reuniões entre governantes e povos indígenas.

Desse modo, é extensa a proteção internacional concedida ao direito a consulta prévia, livre e informado, havendo consenso acerca da sua imprescindível efetivação para que se preserve a existência dos povos indígenas, sendo obrigação do Brasil respeitá-lo. 


\section{2 - O SISTEMA INTERAMERICANO E A POSIÇÃO DA CORTE INTERAMERICANA DE DIREITOS HUMANOS NA PROTEÇÃO DOS DIREITOS DOS POVOS INDÍGENAS}

O sistema interamericano de direitos humanos ainda não possui um documento específico destinado à proteção dos povos indígenas, existindo, apenas, um projeto para elaboração da Declaração Americana dos Povos Indígenas que é debatido na Comissão Interamericana desde os anos 90 (AYLWIN, 2014, p. 291).

No entanto, a Convenção Interamericana de Direitos Humanos (OEA, 1969) prescreve importantes direitos humanos que podem ser e são utilizados pelos povos indígenas à defesa de seus interesses, o que se observa pela própria jurisprudência da Corte Interamericana de Direitos Humanos.

Esta Convenção, também conhecida como Pacto de San José da Costa Rica, foi adotada pela Organização dos Estados Americanos (OEA), na Conferência Interamericana sobre Direitos Humanos, em 1969, tendo sido ratificada pelo Brasil em 1992, por meio do Decreto $n^{\circ} 678$.

Dentre as suas disposições, destaca-se o direito: ao reconhecimento da personalidade jurídica $\left(\operatorname{art.~} 3^{\circ}\right)$; à vida $\left(\operatorname{art.~} 4^{\circ}\right)$; à integridade pessoal (art. $\left.5^{\circ}\right)$; à liberdade e segurança pessoais (art. $7^{\circ}$ ); ao respeito da honra e ao reconhecimento da dignidade (art. 11.1); à liberdade de consciência e de religião (art. 12); à liberdade de pensamento e de expressão (art. 13); à propriedade privada (art. 21); políticos, como a participação da condução de assuntos políticos (art. 23); e à igualdade perante a lei (art. 24).

Tais direitos humanos já foram empregados à questão indígena, como se verifica em diversos julgados da Corte Interamericana.

A Corte Interamericana de Direitos Humanos é um órgão judicial autônomo da OEA, que possui funções consultiva e contenciosa, composta por sete juízes dos Estados membros desta organização que tenham autoridade moral e conhecimento em matéria de direitos humanos (art. 52-1). Tem a competência para analisar qualquer caso relativo à interpretação e aplicação dos dispositivos entabulados na Convenção Interamericana (art. 62-1), podendo assegurar ao prejudicado o gozo do seu direito ou liberdade violados, estabelecer a reparação das consequências oriundas da violação e impor indenização justa à parte lesada (art. 63-1).

Em Moiwana vs. Suriname, a Corte, com base no art. 12 da CADH, determinou aos povos indígenas ou tribais o direito a enterrar seus mortos e celebrar os ritos funerais consoante suas crenças religiosas (ESTUPINÃN SILVA \& IBÁÑEZ RIVAS, 2014, p. 333). Já em 
Mayagana (Sumo) Awas Tingini vs. Nicaragua, fundamentando-se no art. 21 da CADH, a Corte consagrou aos povos indígenas o direito à propriedade coletiva sobre as terras e a viver livremente em seus territórios, como também reconheceu a relação espiritual e cultural mantida com suas terras, essencial à preservação dos seus costumes e sua transmissão às futuras gerações (ESTUPINÃN SILVA \& IBÁÑEZ RIVAS, 2014, p. 334).

Pela leitura da Convenção Interamericana de Direitos Humanos, não encontramos previsão expressa acerca do direito à consulta livre, prévia e informada, porém a Corte garantiu esse direito aos povos indígenas pela interpretação conjunta de artigos da Convenção, atribuindo sentindo e alcance a esse direito (ESTUPINÃN SILVA \& IBÁÑEZ RIVAS, 2014, p. 338).

No caso Saramaka vs. Suriname (CIDH, 2007), que trata das violações cometidas pelo Estado por não adotar medidas efetivas para reconhecer o direito ao uso e gozo dos territórios que essa comunidade ocupa tradicionalmente, ficou consagrado o direito à consulta aos povos indígenas e tribais.

A Corte reconheceu o dever dos Estados em assegurar aos povos indígenas e tribais a participação efetiva, conforme seus costumes e tradições, nos projetos de desenvolvimento, investimento, exploração e extração a serem implementados em seus territórios. Sustentou que o Estado tem a obrigação de consultar ativamente esses grupos, por meio de procedimentos culturalmente adequados, sempre baseada na boa-fé, apresentando todos as informações do projeto, a fim de se chegar a um acordo.

Nesses processos de participação e de consulta, a Corte entendeu que os povos indígenas e tribais devem ser comunicados acerca de todos os ricos possíveis, de todos os impactos ambientais e sociais que podem ser gerados pelos projetos de exploração. E para que esses projetos possam ser aprovados, faz-se imprescindível, ainda, a obtenção do consentimento livre, prévio e informado desses povos, como forma de preservar as suas características e de não afetar sua existência.

Outro caso no qual a Corte tratou do direito à consulta, foi em o Povo Indígena Kichwa de Sarayaku vs. Equador (CIDH, 2012). O objeto da controvérsia girava em torno da autorização concedida, pelo Estado, a uma empresa petrolífera privada para realizar atividades de exploração e extração de petróleo no território daquele grupo, nos anos 90, sem a devida consulta e consentimento dos povos indígenas afetados.

$\mathrm{O}$ início desse processo de exploração ocasionou riscos à referida comunidade indígena, em decorrência da utilização de explosivos de alta potência nas suas propriedades, o 
que lhes impediam de buscar os meios necessários à subsistência, bem como limitavam o exercício dos direitos a livre circulação e expressão da cultura.

Reconhecendo a especial relação que os povos indígenas mantêm com as suas terras ancestrais e seus recursos naturais, imprescindível à preservação da sua cosmovisão, para que sejam implementados projetos de desenvolvimento ou investimento nesses territórios, a Corte determinou: a realização de um processo participativo adequado que garanta o direito à consulta; a efetivação de um estudo de impacto ambiental; e partilhar de maneira equânime os benefícios advindos da exploração dos recursos naturais (CIDH, 2012).

A sentença declarou que o direito à consulta dos povos indígenas e tribais está baseado no respeito ao direito à cultura própria ou identidade cultural. Assim, em uma sociedade que se pretende ser plural, multicultural e democrática, é fundamental garantir às comunidades indígenas a participação nas tomadas de decisões que afetem seus interesses, como o direito à propriedade comunal.

Afirmou-se a obrigação do Estado em assegurar o direito à consulta prévia como forma de permitir o livre e pleno exercício dos direitos estipulados na Convenção Interamericana de Direitos Humanos (art. 1.1). Dessa forma, tem o encargo de criar mecanismos de diálogos efetivos e confiáveis com os povos indígenas nos processos de consulta e de participação, por meio das instituições representativas, processos esses que devem ser realizados desde as primeiras etapas da elaboração e planejamento da medida proposta, para que possam realmente interferir nas tomadas de decisões, conforme determinam as normas internacionais.

Na decisão (CIDH, 2012), a Corte institui como requisitos mínimos para que uma consulta seja considerada válida: o caráter preventivo da consulta; a boa-fé e a intenção de se chegar a um acordo; consulta adequada e acessível; o estudo do impacto ambiental; e a consulta fundamentada.

A consulta deverá ser realizada antes de se tomar a medida ou executar o projeto que possa afetar a comunidade indígena, a fim de que haja tempo suficiente à discussão interna nos grupos e à oferta de uma adequada resposta ao Estado. Quanto às medidas legislativas, a participação indígena tem que ocorrer desde a etapa de produção normativa, e não se limitar a propostas, para permitir a influência efetiva desses povos na elaboração dos textos normativos.

A boa-fé exige o estabelecimento de um diálogo entre as partes baseado na confiança e no respeito mútuos, evitando-se qualquer tipo de coerção aos povos indígenas como forma de pressionar uma autorização ou aquiescência. Não deve ser uma mera formalidade, mas garantir 
a efetiva participação destes grupos, para se chegar a um consenso em relação à medida proposta.

Ainda, a consulta deverá ser adequada e acessível, ou seja, será processada em conformidade com os costumes e tradições dos povos indígenas envolvidos, bem como terá que oferecer mecanismos apropriados para que os membros desses povos possam compreender e se fazer compreendidos, como prevê a Convenção da OIT.

O Estado também está obrigado a realizar um estudo prévio de impacto ambiental e social, apresentando todos os possíveis danos que o projeto de desenvolvimento ou investimento podem causar à comunidade indígena. Esse estudo deverá ser realizado antes de outorgar qualquer concessão dentro do território de um povo indígena, sendo elaborado em consonância às normas internacionais e às boas práticas, como também respeitando a cultura indígena. Tal obrigação visa garantir a esses povos as informações e conhecimentos necessários para decidirem se aceitam ou não determinado projeto, sem que isso importe em denegação de sua própria subsistência.

Por fim, a Corte (CIDH, 2012) exigiu que a consulta seja fundamentada, isso quer dizer que o Estado tem o dever de fornecer todas informações aos povos indígenas, incluído os riscos ambientais e de salubridade que os projetos oferecem, mantendo-se uma cominação constante entre as partes.

A jurisprudência da Corte Interamericana de Direitos Humanos, principalmente nos casos Saramaka vs. Suriname e Povo Indígena Kichwa de Sarayaku vs. Equador, traz importante definição acerca do direito à consulta prévia, livre e informada pertencente aos povos indígenas e tribais. Aponta os elementos que a caracterizaria como adequada à proteção da existência, da identidade cultural e das terras desses povos. Discorre sobre a forma como ela deve ser efetivada, ressaltando ser obrigação dos Estados cumprir esse procedimento sob pena de responsabilização por violação a direitos humanos.

\section{3 - O DIREITO À CONSULTA NO ESTADO BRASILEIRO}

Um dos mais controversos projetos de exploração implementados no Brasil que afetam as comunidades indígenas é a construção do Complexo Hidrelétrico de Belo Monte, no Estado do Pará.

O processo de licenciamento foi e ainda é objeto de diversas demandas judiciais, em razão dos graves impactos sociais e ambientais que este grande projeto causa à região, 
prejudicando principalmente os povos indígenas localizados na bacia do Rio Xingu. E uma das principais críticas se refere à falta de participação e de consulta a esses povos indígenas, especialmente nas primeiras etapas do empreendimento.

O Tribunal Regional Federal da $1^{\mathrm{a}}$ Região (TRF-1) julgou inválido o Decreto Legislativo $n^{\circ} 788 / 2005$ que autorizava o Poder Executivo a implantar o projeto hidrelétrico de Belo Monte a ser desenvolvido pela Centrais Elétricas Brasileiras - ELETROBRAS, em virtude de descumprir a obrigação do direito à consulta aos povos indígenas (BRASIL, TRF1, 000070988.2006.4.01.3903, 2012).

O Tribunal sustentou que o mencionado Decreto Legislativo previa que a consulta aos povos indígenas somente ocorreria em momento posterior à permissão do desenvolvimento do projeto, não seria prévia, como exige a Convenção no 169 da OIT. Ainda, viola o art. 231, § $3^{\circ}$ da Constituição Federal de 1988 (CF/88) que obriga a consulta às comunidades afetadas, para que o aproveitamento de recursos hídricos, incluído o potencial energético, possa ser autorizado.

O Decreto foi considerado antidemocrático e autoritário, pelo fato de aprovar projeto de exploração sem a participação e a consulta prévia aos povos indígenas, como também sem antes elaborar estudo prévio de impacto ambiental e social com relatório conclusivo que seria informativo às comunidades afetadas. Assim, o projeto de Belo Monte teria sido imposto aos povos indígenas, sem que fossem ouvidos, tampouco pudessem exercer algum tipo de influência.

A Comissão Interamericana de Direitos Humanos solicitou, em 01/04/2011, ao governo brasileiro a suspensão imediata do processo de licenciamento do projeto da Usina Hidrelétrica de Belo Monte (CIDH, 2011). Determinou que o Estado realizasse processos de consulta aos povos indígenas afetados em conformidade com os padrões internacionais, ou seja, de maneira prévia, livre, informada, de boa-fé, culturalmente adequada, com objetivo de chegar a um acordo. Para que a consulta seja informativa, institui, ainda, o acesso a um estudo de impacto social e ambiental do projeto, traduzido para o idioma da comunidade indígena envolvida.

Em outro caso, o TRF-1 também determinou a imediata suspenção do licenciamento ambiental e das obras de execução da Usina Hidrelétrica Teles Pires, no Estado do Mato Grosso, até que se realize o Estudo do Componente Indígena (ECI) (BRASIL, TRF1, 000589181.2012.4.01.3600, 2013). 
Este empreendimento hidrelétrico ocasionou diversos danos aos povos indígenas da região (Kayabi, Munduruku e Apiaká), como a inundação das corredeiras das Sete Quedas, que constitui patrimônio cultural e religioso da tribo Munduruku, e o barramento do Rio Teles Pires, área de reprodução de peixes migratórios (piraíba, pintado, pacu, pirarara e matrinxã) que serve de base alimentar dos povos dessa localidade.

Apesar de afetar diretamente a vida das comunidades indígenas, durante o processo de licenciamento desse projeto não lhes foram garantindo o direito à consulta prévia, livre e informada, representando mais um caso de violação ao art. $231, \S 3^{\circ}$, da $\mathrm{CF} / 88$ e ao art. $6^{\circ}$ da Convenção no 169 da OIT.

Ademais, o Estudo e Relatório de Impacto Ambiental (EIA/RIMA) não teria levado em consideração o Estudo do Componente Indígena (ECI), isto é, não se realizou uma análise prévia sobre as possíveis consequências e danos que a construção da hidrelétrica geraria aos povos indígenas da região. Aprovou-se o projeto de exploração com total desprezo e desrespeito aos interesses desses povos, motivo pelo qual foi a suspenso o referido licenciamento.

A instalação da Usina Hidrelétrica de PHC Salto Belo/Sacre2 impactou negativamente os povos residentes na Terra Indígena Utiariti, especialmente as aldeias Sacre II e Bacaval. O TRF-1 reconheceu que não foi assegurado aos povos indígenas o direito à consulta adequada, tampouco realizado estudo prévio de impacto ambiental (BRASIL. TRF1. 000242038.2004.4.01.3600, 2013. Ordenou-se, portanto, a apuração dos danos causados e sua consequente reparação, e, mesmo que tardiamente, a efetuação do Estudo e do Relatório de Impacto Ambiental (EIA/RIMA) e a realização de consultas aos povos indígenas afetados pelo empreendimento.

Em relação ao projeto de construção da Usina Hidrelétrica de São Luís de Tapajós, que se pretende implementar na Bacia dos Rios Tapajós e Jamanxim, o Superior Tribunal de Justiça (STJ) entendeu que meros estudos preliminares acerca da viabilidade do empreendimento não afetam diretamente os interesses das comunidades indígenas, não se exigindo a consulta dos povos indígenas (BRASIL, STJ, 0107879-58.2013.3.00.0000, 2013). O que somente seria obrigatório para o início da execução do projeto.

No entanto, deve ser garantida a consulta aos povos indígenas desde as primeiras etapas do processo de licenciamento, e não somente para início da execução do projeto, a fim de se ampliar o campo participativo dessas comunidades e criar condições necessárias para que elas possam interferir nas tomadas de decisões, bem como proteger suas tradições e costumes. 
Até porque os estudos de viabilidade já representam interferências no cotidiano dos indígenas, devendo ser iniciado os debates.

Os casos analisados demonstram que o direito à consulta livre, prévia e informada não vem sendo efetivado aos povos indígenas pelo Estado brasileiro. Notadamente, nos grandes projetos implementados na Região Amazônica, como os empreendimentos hidrelétricos, em que o interesse econômico se sobrepõe aos direitos humanos dessas comunidades.

Não vêm sendo realizados processos de consultas de acordo com os padrões internacionais. Não são oferecidos aos povos indígenas mecanismos que permitam interferir na adoção das medidas que lhes afetem diretamente, como também meios culturalmente adequados de diálogo, que levem em consideração seus costumes, tradições e cosmovisão. E quando audiências públicas são realizadas com as comunidades indígenas, representam meras formalidades, as suas reivindicações não são atendidas, e há dificuldade na comunicação entre as partes.

Esse cenário causa graves prejuízos aos povos indígenas, que tem sua existência, sua identidade cultural e suas terras ameaçadas. Cabe, assim, ao Estado efetivar os compromissos internacionais assumidos, principalmente o art. $6^{\circ}$ da Convenção $n^{\circ} 169$ da OIT que estipula o direito à consulta aos povos indígenas e tribais.

\section{CONSIDERAÇÕES FINAIS}

O presente trabalho observou que os povos indígenas são grupos vulnerabilizados e marginalizados, dadas as constantes violações a direitos humanos pelos quais são vítimas. Sofreram com processos históricos de expropriação de terras e de perda da identidade cultural, razão pela qual necessitam de proteção especial da comunidade internacional.

Constituem povos com tradições, cosmovisões e modos de viver próprios, que lhes diferenciam de todo o restante da sociedade, como, por exemplo, a relação espiritual e coletiva que mantém com suas terras e recursos naturais, porém estão em constante ameaças, especialmente em razão dos grandes projetos econômicos de exploração dos recursos naturais.

Diante disso, são reconhecidos às comunidades indígenas, internacionalmente, fundamentais direitos humanos. Dentre eles, destacou-se a análise do direito de participação nas tomadas de decisões e à consulta prévia, livre e informada, previstos na Convenção $\mathrm{n}^{\circ} 169$ da OIT e na Declaração das Nações Unidas sobre o Direito dos Povos Indígenas, como forma 
de assegurar que suas reivindicações sejam ouvidas e atendidas quanto às medidas, administrativas ou legislativas, que afetem seus interesses.

Verificou-se, também, a importância dos Mecanismos Internacionais de Direitos Humanos à proteção dos direitos dos povos indígenas, eis que realizam estudos, visitas oficiais, relatórios, reuniões e recomendações acerca do direito à consulta.

A imprescindível interpretação dada pela Corte Interamericana de Direito Humanos ao direito à consulta, conferindo conteúdo e alcance ao mesmo no julgamento dos casos Saramaka vs. Suriname e Povo Indígena Kichwa de Sarayaku vs. Equador. Principalmente, pelo fato de impor requisitos mínimos ao procedimento de consulta, quais sejam: o caráter preventivo da consulta; a boa-fé e a intenção de se chegar a um acordo; consulta adequada e acessível; o estudo do impacto ambiental; e a consulta fundamentada.

Por fim, o estudo dos casos de empreendimentos hidrelétricos implementados na Amazônia, como o Complexo Hidrelétrico de Belo Monte, revela o quanto o direito à consulta livre, prévia e informada carece de efetividade no Brasil. O Estado não cumpre a obrigação de oferecer mecanismos culturalmente adequados de consulta aos povos indígenas, que não possuem qualquer poder de influir nas tomadas de decisões que afetem seus interesses.

Assim, é dever do Poder Público aperfeiçoar os meios de consultas e de participação dos povos indígenas, em consonância aos padrões internacionais exigidos, levando-se em conta as tradições e costumes desses povos, a fim de que a sua identidade cultural seja preservada.

\section{REFERÊNCIAS}

AYLWIN, José. “Los derechos de los pueblos indígenas em América Latina: Avances jurídicos y brechas de implementación” In BELTRÃO, Jane Felipe; BRITO FILHO, Jose Claudio Monteiro de; GÓMEZ, Itziar; PAJARES, Emilio; PAREDES, Felipe; ZÚÑIGA, Yanira (Coords.). Derechos humanos de los grupos vulnerables, 2014, p. 285-314. Disponível em: <http://www.upf.edu/dhes-alfa/materiales/>. Acesso em: 12 jan. 2016.

BELTRÃO, Jane Felipe; OLIVEIRA, Assis de Costa. "Movimentos, Povos \& Cidadanias Indígenas: Inscrições Constitucionais e Direitos Étnicos na América Latina" In BELTRÃO, Jane Felipe; BRITO FILHO, Jose Claudio Monteiro de; GÓMEZ, Itziar; PAJARES, Emilio; PAREDES, Felipe; ZÚÑIGA, Yanira (Coords.). Derechos humanos de los 
grupos vulnerables, 2014, p. 251-284. Disponível em: <http://www.upf.edu/dhesalfa/materiales/>. Acesso em: 12 jan. 2016.

BRASIL, Superior Tribunal de Justiça. Agravo Regimental na Suspensão de Liminar e de Sentença - 0107879-58.2013.3.00.0000, Relator Ministro Presidente do STJ, Data de Julgamento: 19/06/2013, Data de Publicação: DEJT 26/06/2013. Disponível em: $<$ https://ww2.stj.jus.br/processo/pesquisa/?src=1.1.3\&aplicacao=processos.ea\&tipoPesquisa=t ipoPesquisaGenerica\&num_registro=201301078790>. Acesso em: 14 jan. 2016.

BRASIL, Supremo Tribunal Federal. Medida Cautelar na Ação Direta de Inconstitucionalidade - 1675, Relator Ministro: Sepúlveda Pertence, Data de Julgamento: 24/09/1997, Tribunal Pleno, Data de Publicação: DEJT 19/09/2003. Disponível em: <http://www.stf.jus.br/portal/jurisprudencia/listarJurisprudencia.asp?s1=\%28ADI+n\%BA+16 75+\%29\&base=baseAcordaos\&url=http://tinyurl.com/zp6lyjr $>$. Acesso em: 11 jan. 2016.

BRASIL, Supremo Tribunal Federal. Recurso Extraordinário - 3497031, Relator Ministro: Gilmar Mendes, Data de Julgamento: 04/06/2009, Tribunal Pleno, Data de Publicação: DEJT 05/06/2009. Disponível em: <http://www.stf.jus.br/portal/jurisprudencia/pesquisarJurisprudencia.asp>. Acesso em: 11 jan. 2016.

BRASIL, Tribunal Regional Federal da $1^{\text {a }}$ Região. Agravos Regimentais na Apelação Cível - 0005891-81.2012.4.01.3600, Relator Desembargador Federal: Souza Prudente, Data de Julgamento: 09/10/2013, $5^{\text {a }}$ Turma, Data de Publicação: DEJT 29/10/2013. Disponível em: $<$ http://arquivo.trf1.jus.br/PesquisaMenuArquivo.asp?p1=58918120124013600\&pA=\&pN=5 8918120124013600>. Acesso em: 14 jan. 2016.

BRASIL, Tribunal Regional Federal da $1^{a}$ Região. Apelação Cível na Ação Civil Pública - 0002420-38.2004.4.01.3600, Relator Desembargador Federal: Souza Prudente, Data

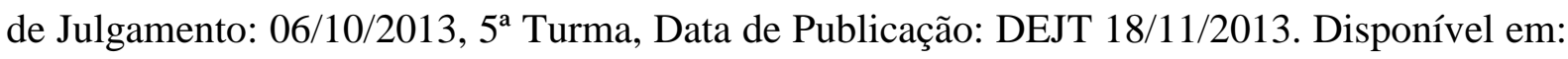
<http://arquivo.trf1.jus.br/PesquisaMenuArquivo.asp?p1=200436000024198\&pA=20043600 0024198\&pN=24203820044013600>. Acesso em: 14 jan. 2016. 
BRASIL, Tribunal Regional Federal da $1^{\text {a }}$ Região. Embargos de Declaração na Apelação Cível - 0000709-88.2006.4.01.3903, Relator Desembargador Federal: Souza

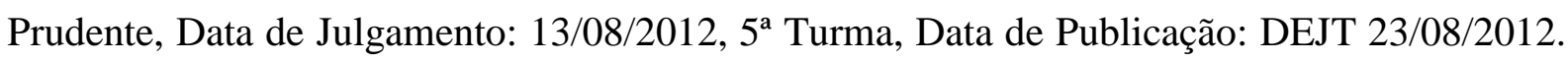
Disponível em: <http://processual.trf1.jus.br/consultaProcessual/processo.php?trf1_captcha_id=5f754ec628b1 d3c07950e04efef9d5c1\&trf1_captcha=n3xt\&enviar=Pesquisar \&proc $=0000709882006401390$ 3\&secao=TRF1>. Acesso em: 14 jan. 2016.

BRASIL. Decreto n. 5.051, de 19 de abril de 2014. Promulga a Convenção no 169 da Organização Internacional do Trabalho - OIT sobre Povos Indígenas e Tribais. Disponível em: <http://www.planalto.gov.br/ccivil_03/_ato2004-2006/2004/decreto/d5051.htm>. Acesso em 12 jan. 2016

BURGER, Julian. "La protección de los pueblos indígenas en el sistema internacional" In BELTRÃO, Jane Felipe; BRITO FILHO, Jose Claudio Monteiro de; GÓMEZ, Itziar; PAJARES, Emilio; PAREDES, Felipe; ZÚÑIGA, Yanira (Coords.). Derechos humanos de los grupos vulnerables, 2014, p. 220-250. Disponível em: <http://www.upf.edu/dhesalfa/materiales/>. Acesso em: 12 jan. 2016.

CORTE INTERAMERICANA DE DERECHOS HUMANOS. Caso del Pueblo Indígena kichwa de Sarayaku vs. Ecuador. Sentencia de 27 de junio de 2012 (Fondo y Reparaciones). Disponível em: <http://corteidh.or.cr/docs/casos/articulos/seriec_245_esp.pdf>. Acesso: 09 jan. 2016.

CORTE INTERAMERICANA DE DERECHOS HUMANOS. Caso del Pueblo Saramaka vs. Surinam. Sentencia del 28 de noviembre de 2007 (Excepciones Preliminares, Fondo, Reparaciones y Costas). Disponível <http://www.corteidh.or.cr/docs/casos/articulos/seriec_172_esp.pdf>. Acesso: 09 jan. 2016.

COURTIS, Christian. “Anotações sobre a aplicação da Convenção 169 da OIT sobre povos indígenas por tribunais da América Latina". SUR. Revista Internacional de Direitos Humanos, n. 10, jun. 2009, p. 53-81. Disponível em: <http://www.scielo.br/sur〉. Acesso em: 12 jan. 2016. 
ESTUPIÑAN SILVA, Rosmerlin; IBÁÑEZ RIVAS, Juana María. “La jurisprudencia de la Corte Interamericana de Derechos Humanos en materia de pueblos indígenas y tribales" In BELTRÃO, Jane Felipe; BRITO FILHO, Jose Claudio Monteiro de; GÓMEZ, Itziar; PAJARES, Emilio; PAREDES, Felipe; ZÚÑIGA, Yanira (Coords.). Derechos humanos de los grupos vulnerables, 2014, p. 316-356. Disponível em: <http://www.upf.edu/dhesalfa/materiales/>. Acesso em: 12 jan. 2016.

MAUÉS, Antonio Moreira. "Supralegalidade dos tratados internacionais de direitos humanos e interpretação constitucional” In LOPES, Ana Maria D’ Ávila; MAUÉS, Antonio Moreira (Orgs.). A eficácia nacional e internacional dos direitos humanos. Rio de Janeiro: Lumen Juris, 2013, p. 27-50.

ORGANIZAÇÃO DAS NAÇÕES UNIDAS. Declaração das Nações Unidas sobre o Direito dos Povos Indígenas. Disponível em: http://www.un.org/esa/socdev/unpfii/documents/DRIPS_pt.pdf> Acesso em: 12 jan. 2016

ORGANIZAÇÃO DAS NAÇÕES UNIDAS. Estudio definitivo sobre los pueblos indígenas y el derecho a participar en la adopción de decisiones. Informe del Mecanismo de expertos sobre los derechos de los pueblos indígenas. Disponível em: $<$ http://www.ohchr.org/Documents/Issues/IPeoples/EMRIP/finalreportStudyIPRightParticipat e_sp.pdf>. Acesso em: 10 jan. 2016.

ORGANIZAÇÃO DAS NAÇÕES UNIDAS. Foro Permanente para las Cuestiones Indígenas. Informe sobre el $14^{\circ}$ período de sesiones (20 de abril a 1 de mayo de 2015). Disponível em: <http://www.acnur.org/t3/fileadmin/Documentos/BDL/2015/10087.pdf?view=1>. Acesso em: 10 jan. 2016.

ORGANIZAÇÃO DAS NAÇÕES UNIDAS. Relatório sobre a situação dos direitos humanos e das liberdades fundamentais indígenas. James Anaua em missão ao Brasil de 18 a 25 de agosto de 2008 em: $<$ https://pib.socioambiental.org/files/file/PIB_institucional/Anaya_Brasil_anexo.pdf >.Acesso em: 11 de jan. 2016. 
ORGANIZAÇÃO DOS ESTADOS AMERICANOS. Convenção Americana sobre Direitos Humanos.

Disponível

em:

<https://www.cidh.oas.org/basicos/portugues/c.convencao_americana.htm>. Acesso em: 12 jan. 2016

ORGANIZAÇÃO DOS ESTADOS AMERICANOS. Medidas cautelares outorgadas pela CIDH no ano 2011. MC 382/10 - Comunidades Indígenas da Bacia do Rio Xingu, Pará, Brasil. Disponível em: <http://www.cidh.oas.org/medidas/2011.port.htm>. Acesso em: 13 jan. 2016.

STAVENHAGEN, Rodolfo. “Caso de la Comunidad Mayagna (Sumo) Awas Tingui Vs. Nicaragua. Sentencia de 31 de maio de 2011" In Corte Interamericana de Derechos Humanos, 2011. Disponível em: <http://www.corteidh.or.cr/docs/casos/articulos/Seriec_79_esp.pdf>. Acesso em: 12 jan. 2016. 